Words: 10,767

\title{
Is there a common pattern to integrate multiple management systems? A comparative analysis between organizations in Greece and Spain
}

\begin{abstract}
The integration of management systems has been mainly studied considering the process within organizations and also comparing the implementation among organizations in the same country. Scarce research has been done comparing the process among countries.

Thus, the aim of this study is to analyze and compare the implementation of the integrated management systems between organizations located in two countries, Greece and Spain, which have different ISO 9001 and ISO 14001 certification rates.

A qualitative method has been applied. Six case studies are presented, three per country, to analyze the aspects of the process and comparing both implementation processes. All organizations have, at least, the ISO 9001 and the ISO 14001 management systems certification. The integration aspects studied are: strategy, methodology, level, audits, benefits and difficulties.

The findings, although exploratory, show that the differing integration aspect among the analyzed organizations is the audits both internal and external. Greek organizations achieve higher levels of internal audits integration rather than external but these levels are lower compared to the audits integration level of the Spanish organizations. The other aspects analyzed followed a similar pattern, i.e., the majority of organizations implement first the quality management system and then the environmental, common elements analysis is the main methodology applied, the level reported show a tendency to full integration and benefits and difficulties highlighted are also similar.

In addition, derived from these results, internal and external factors affecting the integration process have been also discussed for future research: certification rates, top management commitment, internalization of management systems, external auditors' experience and state support. Implications for academia, organizations and certification bodies are also presented. Although the integration of management systems has been analyzed in the literature, this is one of the first studies comparing organizations in countries with different certification rates and analyzing additional factors conditioning the process.
\end{abstract}

Keywords: Integrated management systems, audits, Greece, Spain, certification rates, conditioning factors. 


\section{Introduction}

The implementation and certification of Management Systems (MSs) has continuously increased in the last twenty years (ISO, 2015). Specifically, the certification rates of the ISO 9001 standard for Quality Management Systems (QMSs) and the ISO 14001 standard for Environmental Management Systems (EMSs), keep rising at a worldwide level (ISO, 2015).

The majority of studies on Management System Standards (MSSs) rely on the data provided by the International Organization for Standardization (ISO). Two main aspects can be underscored based on these data. The first is that countries with more experience in certification are those reaching a higher level of MSS diffusion and second, cross-country analyses are mainly based also on comparing the diffusion of ISO 9001 and ISO 14001 certificates (Llach et al., 2011; Marimon et al., 2011). The studies also conclude that MSSs diffusion is conditioned by geographic location and cultural affinity (Albuquerque et al., 2007).

The proliferation of these and other MSs raises the question of whether organizations could integrate their respective MSs into a single and consolidated MS, i.e., an Integrated Management System (IMS). A whole stream of research has been generated to address this question. Pioneers in the field (Karapetrovic, 2003; Karapetrovic and Willborn, 1998a) stressed that "integration makes more sense than disintegration", and, therefore, they urged organizations to integrate rather than manage their MSs separately. Several empirical studies followed and conceptual integration models were composed to support the spread of IMSs in countries across the globe, including but not limited to Spain, Italy, China and Australia (Bernardo et al., 2009; Salomone, 2008; Zeng et al., 2011; Zutshi and Sohal, 2005).

In this sense, IMS research interest, in analogy to the MS research, gradually shifts from the initial implementation and integration of multiple MSs (e.g., Bernardo et al., 2012a; Karapetrovic and Wilborn, 1998a; Zeng et al., 2011), to other aspects more related to the IMS sustainability considering its maintenance (e.g., Almeida et al., 2014;), impact on performance (e.g., Ferrón-Vílchez and Darnall, 2016; González et al., 2014), adding new MSs (e.g., Rocha et al., 2007) and relationship with other managerial practices such as innovation (Hernandez-Vivanco et al., 2016). However, there is a paucity of research on comparative analysis across countries in order to study if the IMS implementation is similar in different countries as no international and certifiable MSS has been published. These studies have been done for MSSs individually, but to the best of the authors' knowledge, only one paper comparing two countries with similar ISO 9001 and ISO 14001 certification rates has been published (Simon and Douglas, 2013).

Thus, the aim of this paper is to analyze and compare the implementation of IMS between organizations located in two countries, Greece and Spain, which have different ISO 9001 and ISO 14001 certification rates. The contribution of this paper is twofold. First, to present the comparison itself that will help in detecting an implementation pattern of the process 
regarding the analyzed organizations and second, to discuss different factors that could affect this process as future research proposals, derived from the results obtained from this study together with the existing literature on this topic.

\section{Literature review}

Several definitions have been proposed for the integration of MSs. The most cited is the one coined by Karapetrovic and Willborn (1998a) and Karapetrovic (2003), who defined an IMS as a "set of interconnected processes that share a pool of human, information, material, infrastructure, and financial resources in order to achieve a composite of goals related to the satisfaction of a variety of stakeholders". The main aspects identified when considering the integration process are (Bernardo et al., 2012b; Domingues et al., 2015): strategy, methodology, level, and auditing systems. The benefits and difficulties encountered during the process are also analyzed. All them are presented in the following paragraphs.

\subsection{Integration strategy}

Integration strategy refers to the sequence of the individual MSs adoption. In the existing literature various strategies are proposed (Karapetrovic, 2002; Karapetrovic and Jonker, 2003), but the most followed is the Karapetrovic and Willborn (1998a)'s proposal of three strategies, i.e., to establish: first the QMS and then the EMS; or first the EMS and then the QMS; or both MSs simultaneously. According to the existing empirical studies, the first strategy is the most followed (e.g., Abad et al., 2014; Bernardo et al., 2012b; Karapetrovic and Casadesús, 2009) and recent research shows that the simultaneous implementation is also possible (Llonch and Bernardo, 2016).

\subsection{Integration methodology}

Several integration methodologies have been proposed by both academic and standardization bodies. Academics have elaborated their own methodologies based either on the integration of MSs elements, i.e. objectives, resources and processes (Karapetrovic and Jonker, 2003) or on composed models (de Oliveira, 2013; Karapetrovic, 2005; Pal Pandi et al., 2016). Karapetrovic et al. (2006) proposed four different methodologies: process map, PDCA, common elements and organizations' own models.

Certain standardization bodies have launched national integration norms, such as in Denmark (Dansk Standard, 2005), Australia and New Zealand (SAI Global, 1999), Spain (AENOR, 2005), and United Kingdom (BSI, 2012). ISO released a handbook providing recommendations to integrate all the MSs implemented by a single organization (ISO, 2008), and has implemented the High Level Structure (HLS), i.e., a common structure in all the new and updated MSSs published that enhances their integration. Thus, it could be expected that the difficulties encountered during the process for differences in common elements or MSSs structure (Bernardo et al., 2012a; Douglas and Glen, 2000) will not be maintained, improving and increasing the integration of MSs. 
In addition, as the models of the updated ISO standards (ISO 9001 and ISO 14001) are explicitly common, the integration process based on common elements analysis will also increase and be easier.

\subsection{Integration level}

To assess the degree of integration, Sampaio et al. (2012) propose four evolution levels towards complete integration: documentation integration, management tools integration, common policies and goals, and common organizational structure (similar to Bernardo et al., 2009). Integration degree can be measured at strategic, tactical and operational level as full, partial or no integration (Asif et al., 2010).

Three integration levels are normally accepted in the literature (Karapetrovic, 2003): not integrated, when multiple MSs are managed separately; partially integrated, when some MSs components are integrated and the rest are kept separated, and fully integrated, when all MSs components are managed as a single system (Abad et al., 2014; Mezinska et al., 2015; Santos et al., 2011). Bernardo et al. (2012b) stress that the implementation order of MSs may condition the level of integration achieved within an IMS, concluding that those organizations implementing both MSs simultaneously achieve higher levels of integration.

\subsection{Integration of audits}

This aspect of the process considers the integration of the internal and external audits. Organizations that have integrated their management systems are expected to carry out integrated audits, at least the internal (Karapetrovic and Willborn, 1998b; Kraus and Grosskopf, 2008; Simon et al., 2014).

According to Karapetrovic and Willborn (2001), auditing based on a systemic approach may lead to benefits, such as the "harmonization and integration of different discipline-specific audits and guidelines for audit”. In addition, joint audits may lead to greater synergies and effectiveness of audits in relation to improved business performance (Karapetrovic and Jonker, 2003) but an inadequate audit methodology could be a barrier to integrate (Hoy and Foley, 2015; Searcy et al., 2012).

Empirical studies report a higher level of integration in the internal than in the external audits (Karapetrovic et al., 2006). To highlight the perspective of the external auditors, Wilkinson and Dale (1998) addressed five certification bodies, the majority of which did not perform integrated audits. More than a decade later, Kafel and Sikora (2010) emphasize that Polish certifying bodies carry out combined audits.

To assess the level of audit integration, four main variables are considered (Bernardo et al., 2010, 2011; Simon et al., 2011). The first is the audit team measured into three levels of integration in which fully integrated means that the same team audits all the MSs, partially 
integrated means that the same team audits some of the MSs and not integrated means that a different team audits each MS. The second variable is the audit time, in which the same levels apply as for the audit team. The audit plan and report are the third variable analyzed (the same levels apply as for the audit team), and finally, the results of the audit is the fourth variable (the same levels apply as for the audit team).

\subsection{Integration benefits and difficulties}

According to the existing literature, the key integration benefits are (Bernardo et al., 2015; Domingues et al., 2015) related to a greater flexibility and opportunities to include other systems (Beckmerhagen et al., 2003), the avoidance of duplication of efforts (Zeng et al., 2011), a better use of synergies between the standards (Simon et al., 2013), and the reduction of audits resources through integrated audits (Beckmerhagen et al., 2003) and multi-function auditors (Douglas and Glen, 2000). Rebelo et al. (2016) analyzed the implementation of the IMS in a single organization and concluded that, among other benefits, the efficiency improved, the organization was leaner, and the coordination of the sustainability pillars (environmental, economic and social) was greater adding value for both the organization and stakeholders.

On the other side, the integration difficulties usually encountered are related to the differences in the general elements of the standards and their specific requirements (Bernardo et al., 2012a), the lack of certification support (Zeng et al., 2007) and resources (Asif et al., 2009; Gianni and Gotzamani, 2015), especially human resources (Karapetrovic et al., 2006), and the problems related to organizational culture (Wilkinson and Dale, 1999).

\subsection{Relationship among the integration aspects and other managerial practices}

All the basic aspects analyzed above are related in figure 1. The figure shows the main elements of all the aspects on the integration process and also their relationship as commented. It focuses on the process each organization could follow, i.e., the implementation pattern.

As commented previously in this section, all these aspects have been widely analyzed individually. The expected changes are marginal as the great majority of organizations with multiple MSs implemented are integrating them, according to the existing empirical studies (see e.g., Simon et al., 2011; Abad et al., 2014). Also, it seems that the HLS implementation could enhance the current implementation process overcoming some of the most highlighted difficulties of the process (see e.g., Bernardo et al., 2012a; Zeng et al., 2007). 


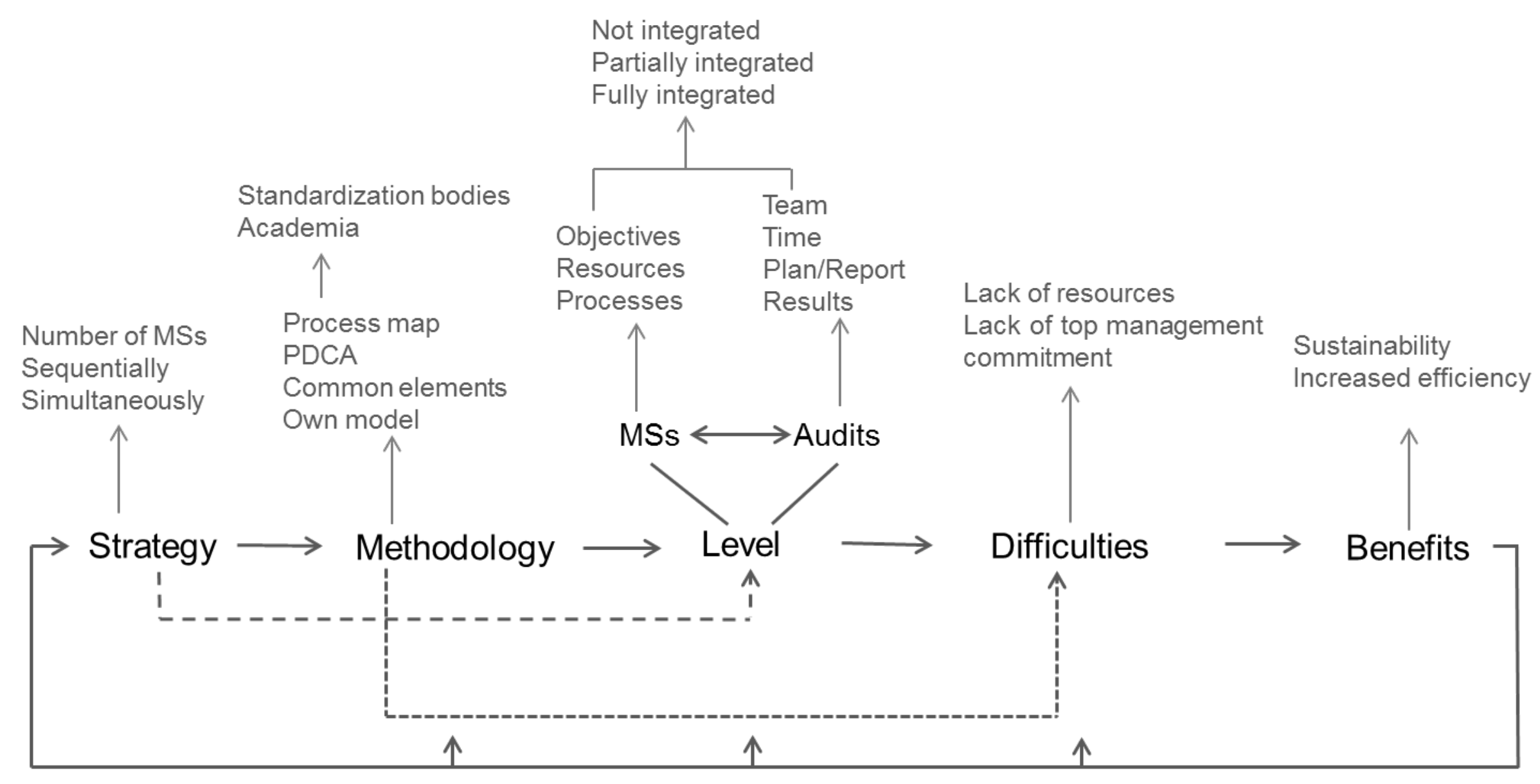

Continuous improvement

Figure 1. Main aspects and their relationship of the integration of MSs process

Source: Own elaboration 
The existing and future literature needs to relate these aspects with other managerial practices to add value to the integration process. For example, other aspects also analyzed are the future maintenance (Rocha et al., 2007), costs of implementation (González et al., 2014), relationship with performance (Ferrón-Vílchez and Darnall, 2016), critical success factors (Almeida et al., 2014), relationship with innovation (Simon and Yaya, 2012; Bernardo, 2014; Hernandez-Vivanco et al., 2016), and stakeholders (Jadudová et al., 2016).

The pattern presented (figure 1), according to the existing literature analyzed in this section, seems to be similar for the majority of organizations. However, there is a lack of crosscountry comparative analyses. Only one paper has been detected in the literature, Simon and Douglas (2013), in which the IMS is compared between Spain and UK. The results of the six case studies (3 per country) show that the main differences are in internal audits, difficulties and benefits, being the English organizations the ones performing better. The analysis was mainly based on the internal aspects of the implementation and no mention is done for the external audits. In addition, in that paper both countries have led the certification rates in recent years (ISO, 2015).

Taking the abovementioned into account, the aim of this paper is to analyze the IMS implementation within organizations in two countries with different certification rates. If the implementation, considering also the external audits not considered in Simon and Douglas (2013) is similar, it could be stated, although with caution, that the certification rate of individual MSs is not conditioning the IMS. But if the implementation is different, these rates should be considered as a conditioning factor of the integration process. Thus, it would mean that the pattern is not the same for the organizations in the countries analyzed. This difference could be in the aspects or in the achievement level of these aspects. Additional conditioning factors could also be identified from this comparison.

\section{Methods}

In order to meet the research objective, six organizations located in these two countries, Greece and Spain, were selected. Case research method is applied, since it allows the detection of causes, processes and behavioral consequences (Yin, 2009). The selected method applies in exploratory research and can "provide a detailed understanding of particular situations which can be used inductively to build a better theory focusing on the gaps and filling” (Siggelkow, 2007). A qualitative approach has been applied as previous studies have mainly based on quantitative methods specifically applying surveys answered by managers or quality systems representatives (see e.g., Abad et al., 2014; Karapetrovic et al., 2006). Sampaio et al. (2011) discussed the extended use of surveys to analyze this topic and the importance of performing other types of data collection as using existing data bases.

The selected cases were examined from a comparative, cross-crountry perspective. Comparative analysis studies the relationship between cases and the variables employed (Keman, 1993). Furthermore, comparative research enables comparing two or more sets of findings to obtain new insights or explanations. Regarding the case studies, the interests and 
goals of comparative analysis often dictate the design of studies with a small number of cases, which sometimes are very few to permit the application of any statistical technique (Ragin, 2014). According to Mak (2015), "in a cross-country comparative research the main objective is to uncover and analyze data similarities and differences by describing the features of the analysis units, such as countries, governments, and economic sectors, for the purpose of potentially enhancing knowledge”, which is the method applied in this paper.

Within this research, the IMS implementation in each organization has been analyzed and then the cases of two countries compared. The unit of analysis is the IMS of each organization. Particularly, in comparative case analysis a distinction is made between the observational and the explanatory unit of analysis (Ragin, 2014). Observational unit refers to the unit used in data collection and data analysis whereas explanatory unit refers to the unit that is used to account for the pattern of results obtained (Ragin, 2014). Following this line of reasoning, within this research framework, the observational unit is the organization's IMS (the relationship is based on organization-level data) and the explanatory unit is state / national (analysis at country-level). Research process is based on the steps followed by Satolo et al. (2013) as described in figure 2.

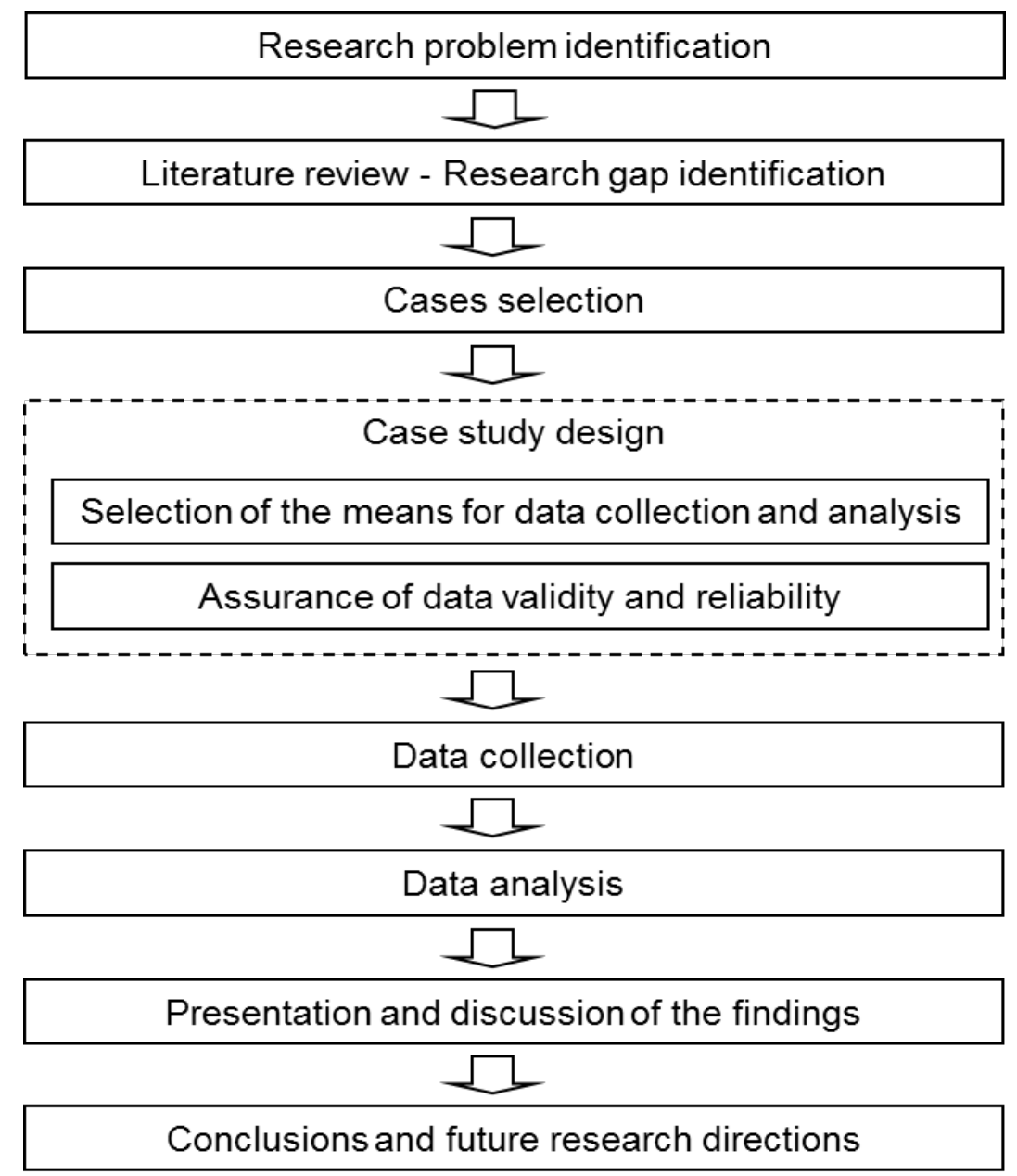

Figure 2. Steps for conducting case-based research

Source: adapted from Satolo et al. (2013) 


\subsection{Countries selection}

Out of the six cases studied (as in Simon and Douglas, 2013), three organizations are active in the region of Catalonia (north east of Spain), while the other three are located in the region of Central Macedonia in Northern Greece. The two countries were selected based on the differences in the number and diffusion level of certifications. Spain has ranked for a long time among the top countries in the world with regard to the number of certifications to both the ISO 9001 and the ISO 14001 standards (ISO, 2015). In contrast, Greece has far lower levels of certification to both standards throughout the same time period (ISO, 2015).

Figures 3 and 4 provide the evolution of ISO 9001 and ISO 14001 certifications per Gross Domestic Product (GDP) in both countries, which is known as "density" or "intensity" (Corbett and Kirsch, 2001; Marimon et al., 2006). The ratio, see equation (1), considers the number of certificates of that country in that year related to the GDP of that country in that year:

$$
\text { Intensity }=\left(\frac{\text { Number of certificates (country, year) }}{\text { GDP (country, year) }} \times 100\right)
$$

GDP is used as a proxy for the volume of certifiable domestic organizations (Prakash and Potoski, 2007).

It is worthy of remark that while the respective ratios in the two countries kept a constant distance over the years (2002-2012), in accordance with the ISO survey data those country ratios tend to converge in the last years (ISO, 2015). This should be taken with caution as ISO pointed in the survey that the Spanish ISO 9001 certificates decrease is "explained partly by 3 important contributors reporting fewer certificates than in 2013” (ISO, 2015), although no other explanation is reported.

Thus, although both countries seem to converge in 2013 regarding the ISO 9001, the previous years' data show the difference between the two countries. Spain has led this ratio and is still in a better position compared to Greece after 2013. 


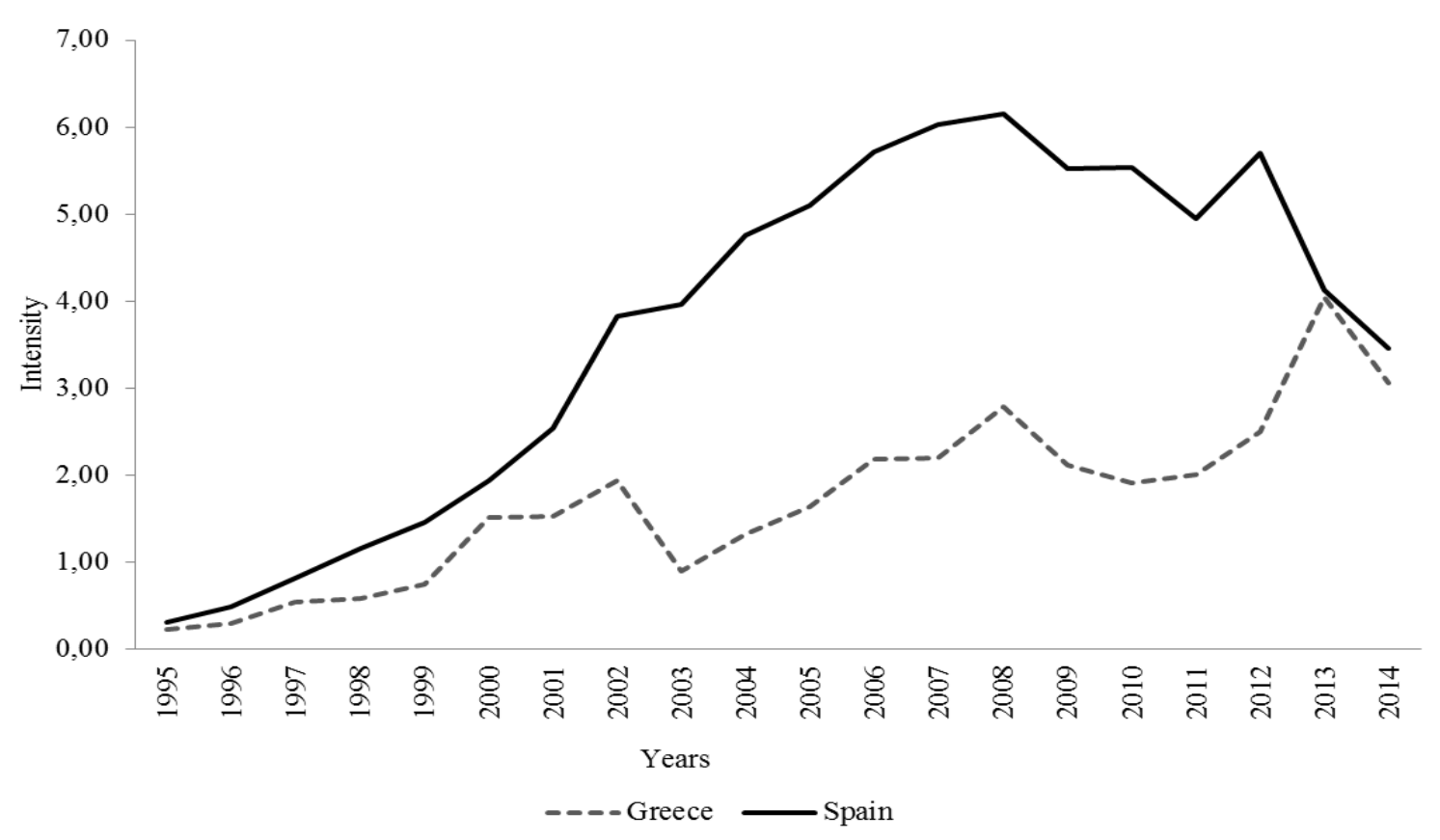

Figure 3. Evolution of ISO 9001 certifications per GDP

Source: ISO (2015) and Eurostat (2016)

ISO 14001 ratio shows a higher and constant difference (figure 4), again with Spain's ratio leading the comparison. Taking the previous into account, it could be stated that Spain has been implementing and certifying both MSSs in a greater intensity than Greece.

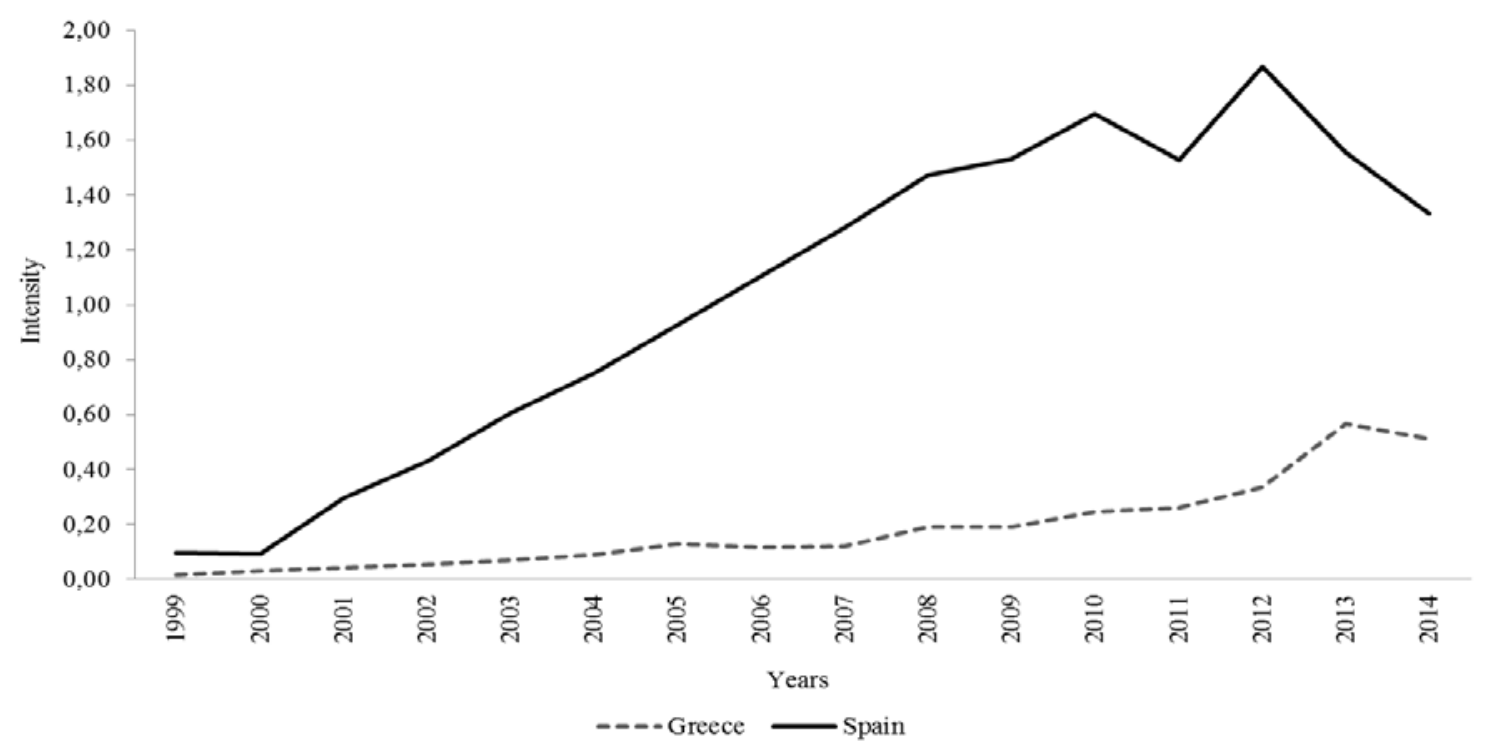

Figure 4. Evolution of ISO 14001 certifications per GDP

Source: ISO (2015) and Eurostat (2016)

This difference in certification rates (relative numbers) allows presenting a different situation than the previous study comparing the IMS implementation (Simon and Douglas, 2013). When this comparison is presented in absolute numbers the difference is greater (see figures 5 and 6). 


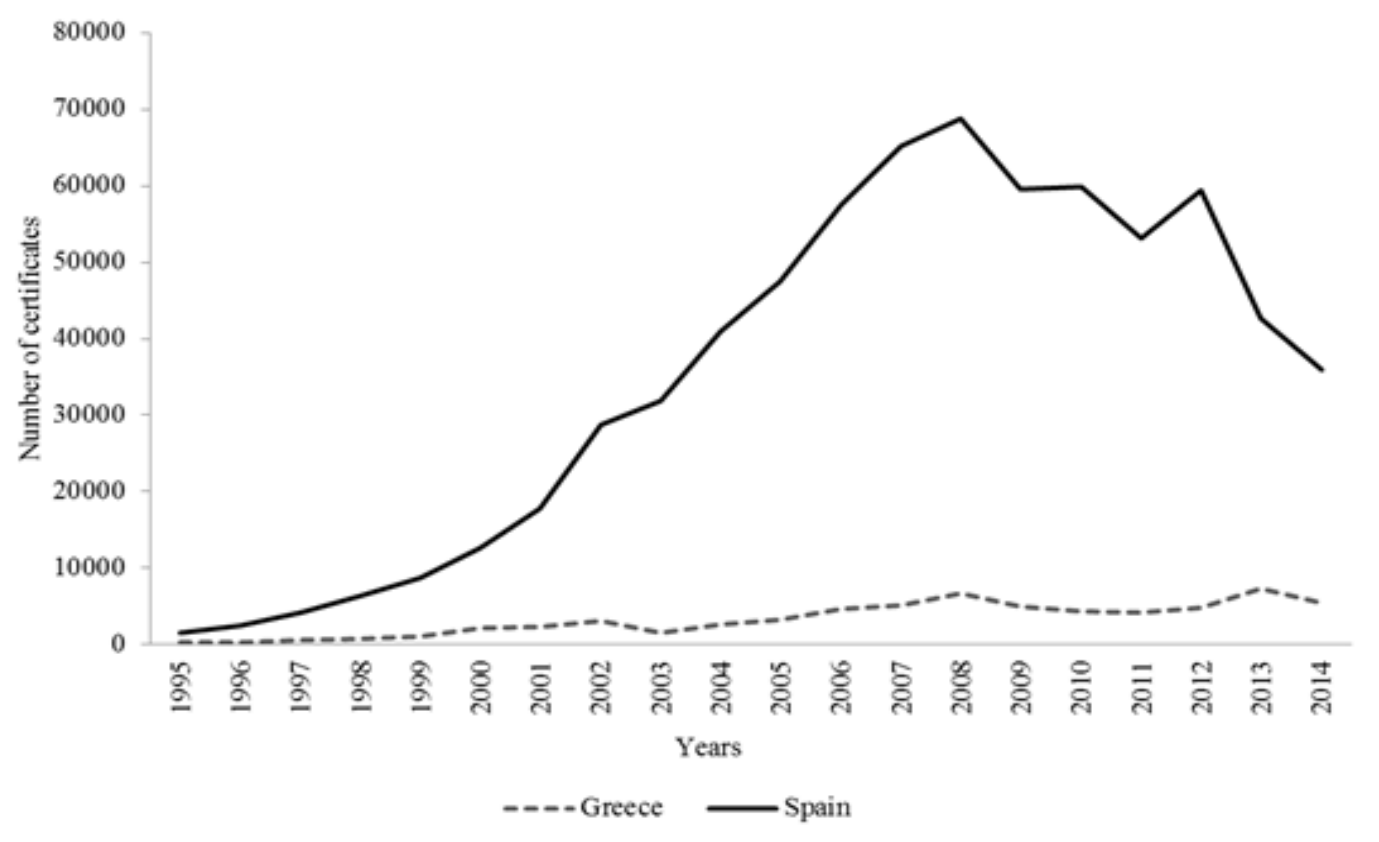

Figure 5. Evolution of ISO 9001 certifications (absolute numbers)

Source: ISO (2015)

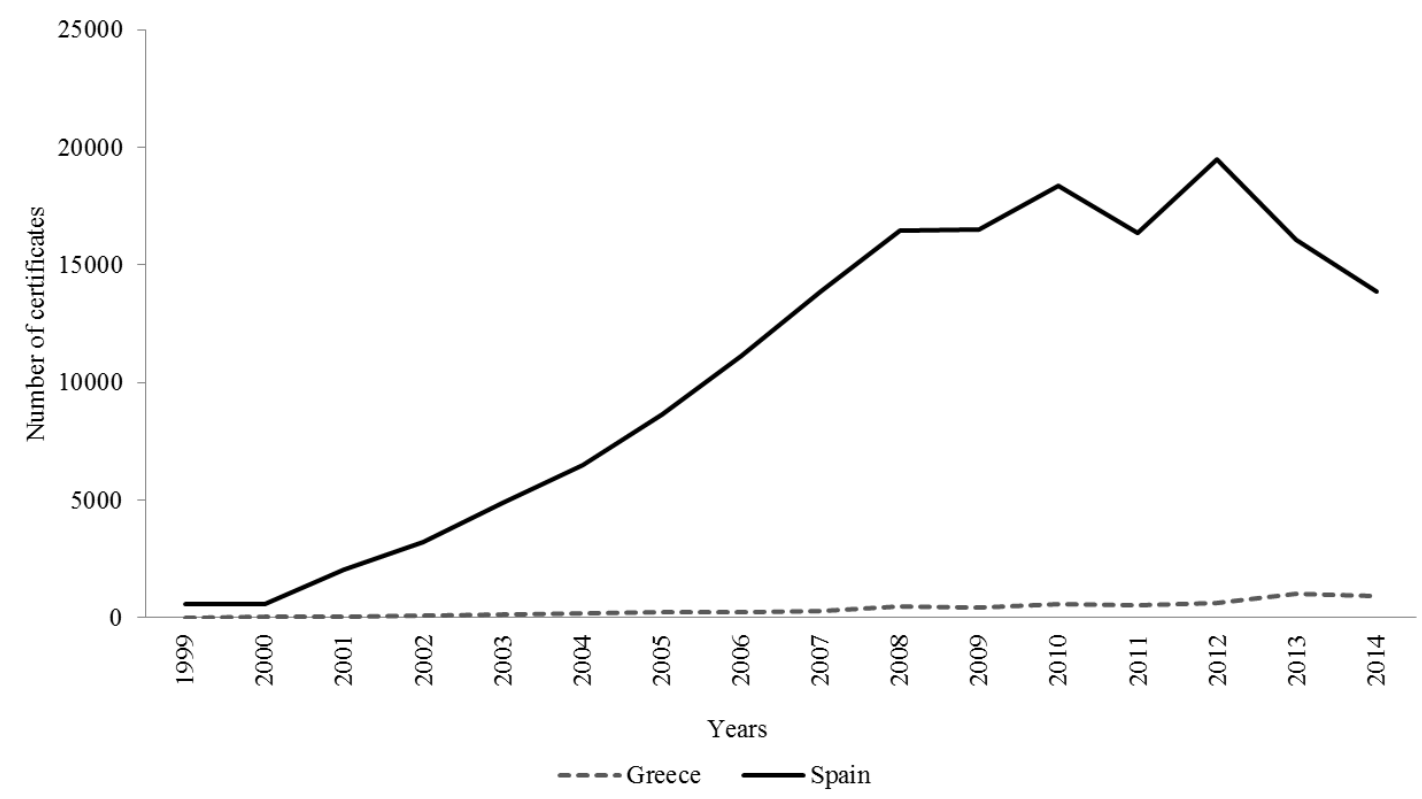

Figure 6. Evolution of ISO 14001 certifications (absolute numbers)

Source: ISO (2015)

\subsection{Cases selection}

All the case companies that participated in the research were certified to at least two MSs, assuring the existence of multiple MSs and, hence, the possibility of their integration. As mentioned, the two MSs considered in this study are the ISO 9001 standard for quality management and the ISO 14001 standard for the environmental management. Thus, the cross-country comparability of findings is ensured. 
Table 1 summarizes the main case characteristics. For confidentiality reasons, the real organizations' names are not used and the six companies have been coded according to their location. Thus, Spanish organizations have been coded as 1S, 2S, and 3S, while the Greek organizations have been coded as 1G, 2G, and 3G.

For the Spanish cases, companies were selected from a previous sample of 179 organizations that had participated in a research project on the integration of MSs in Spain (see, e.g., Karapetrovic et al., 2006; Bernardo et al., 2010). The Spanish companies where chosen from different IMS level clusters (Bernardo et al., 2009). Moreover, using the information of the former research sample it was ensured that the selected organizations integrated their MSs and had experience in the topic under study.

Table 1. Main characteristics of the case organizations

\begin{tabular}{|c|c|c|c|c|c|c|}
\hline \multirow[t]{2}{*}{ Org. } & \multirow[t]{2}{*}{ Production activities } & \multirow{2}{*}{$\begin{array}{l}\text { Organization } \\
\text { type }\end{array}$} & \multirow{2}{*}{$\begin{array}{l}\text { Turnover } \\
\text { (million } € \text { ) }\end{array}$} & \multirow{2}{*}{$\begin{array}{l}\text { Number of } \\
\text { employees }\end{array}$} & \multicolumn{2}{|c|}{ Initial certification year } \\
\hline & & & & & ISO 9001 & ISO 14001 \\
\hline $1 \mathrm{~S}$ & $\begin{array}{l}\text { Manufactures plasticized } \\
\text { vinyl compounds for } \\
\text { electrical cable extrusion, } \\
\text { molding and other materials. }\end{array}$ & $\begin{array}{l}\text { Public limited } \\
\text { organization }\end{array}$ & 31 & 33 & 2001 & 2002 \\
\hline $2 S$ & $\begin{array}{l}\text { Develops and manufactures } \\
\text { chemicals for process } \\
\text { improvement in the } \\
\text { industries of cellulose and } \\
\text { paper. }\end{array}$ & $\begin{array}{l}\text { Public limited } \\
\text { organization }\end{array}$ & 17 & 38 & 2000 & 1999 \\
\hline $3 S$ & $\begin{array}{l}\text { Manufactures lubricants and } \\
\text { hydraulic fluids, e.g., anti- } \\
\text { corrosive, biodegradable } \\
\text { lubricants, etc. }\end{array}$ & $\begin{array}{l}\text { Public limited } \\
\text { organization }\end{array}$ & 53 & 137 & 1994 & 1998 \\
\hline $1 G$ & $\begin{array}{l}\text { Manufactures, among others, } \\
\text { food preservatives, chemical } \\
\text { formulas, etc. }\end{array}$ & $\begin{array}{l}\text { Public limited } \\
\text { organization }\end{array}$ & 5 & 92 & 1996 & 2002 \\
\hline $2 \mathrm{G}$ & $\begin{array}{l}\text { Manufactures aluminum } \\
\text { products for construction, lift } \\
\text { parts, etc. }\end{array}$ & $\begin{array}{l}\text { Public limited } \\
\text { organization }\end{array}$ & 140 & 1700 & 2000 & 2002 \\
\hline $3 G$ & $\begin{array}{l}\text { Flexible packaging, e.g., } \\
\text { bags of snacks, beverage } \\
\text { labels, etc. }\end{array}$ & $\begin{array}{l}\text { Public limited } \\
\text { organization }\end{array}$ & 57 & 269 & 1995 & 2001 \\
\hline
\end{tabular}

Source: Own elaboration

Greek case companies could not be selected in the exact same way, due to the lack of prior empirical research data that would allow clustering the sample units according to their IMS level, similar to the Spanish organizations. Therefore, the Greek cases were chosen from a convenience sample of 15 companies that were willing to take part in the research due to the established trust between the researchers and the organizations, gained from previous collaboration. This trust helped the researchers to have accessibility to the necessary for the study documentation and also assured the readiness of the employees to be interviewed. Furthermore, the selected Greek organizations meet the same minimum requirements for 
participation that apply to the Spanish case organizations, i.e. the implementation of the ISO 9001 and the ISO 14001 and the diversity in size and activity.

\subsection{Data collection and analysis}

Data were collected using a semi-structured questionnaire, widely used in qualitative methodologies (Yin, 2009). Closed- and opened- questions facilitated the information extraction during the interviews by encouraging the employees to expand on the topics. The informants were the employees assigned to manage the MSs, i.e. the quality, environmental and production managers. Certain general managers participated also in the research, since most particularly in family-owned organizations, they were fully aware of and actively involved in MSs integration.

The interview protocol addressed the implementation and maintenance of MSs, including questions on the number and scope of the MSSs adopted, the implementation order or strategy (MSs implemented and date of implementation), the audits (for internal and external: team, time, plan, report, results), the integration level (elements integrated and its degree: no, partial, full), the motives and the anticipated benefits that led to the decision to integrate, the benefits gained (better organization, internal improvement, efficiency, image) and the difficulties encountered (lack of resources, knowledge or top management commitment).

Each interview lasted between 45 to 60 minutes. The field research team was composed by two interviewers, who kept notes during the interviews. Interviews were transcribed and field notes were cross-checked afterwards.

The documents, records and archives of the MSs were accessed and thoroughly assessed in order for the data to be substantiated and completed. Records of the internal and third-party audits, annual management reviews minutes, quality and environmental plans, performance sheets, awards, etc., were used to establish the level of integration of the documented MSs, the integration level of the audits conducted, the IMS benefits - both qualitative and quantitative - and the impediments that slowed down integration or even hampered its completion. Furthermore, multiple sources of information, i.e. interviews, documents, observations and websites, were used to substantiate the level of top management commitment, the human and other resources allocated for the integration and the planning for future adoption of sectoral and/or generic management system standards and business excellence schemes and their merge into the existing IMS.

A qualitative approach was adopted for the data analysis to examine concepts, such as experience in managing MSs and integration, "in terms of their meaning and interpretation in specific contexts of inquiry” (Denzin and Lincoln, 2011). Finally, the collected data was processed and compiled in the form of a written case report for each organization that was sent to each participant for validation. The validated cases are presented in the results section. Data triangulation intended to reduce bias by using multiple sources of evidence, both primary and secondary, including interviews, MS archives and records and websites. 
"Convergent lines of inquiry" ensured construct validity (Yin, 2009). The actions taken to address validity and reliability are summarized in Table 2.

Table 2. Validity and reliability assurance measures

\begin{tabular}{ll}
\hline Validity/Reliability & Measures \\
\hline Internal validity & Specification of a clear research framework \\
& Inferences and pattern matching in relation to prior research \\
& Triangulation of analyzed data and discussion among researchers \\
External validity & Cross case analysis extending previously conducted within-case analysis \\
& Explanation of rational for the case selection \\
& Detailed case background information \\
Reliability & Established interview protocol \\
& Comparable questionnaire items \\
\hline
\end{tabular}

Source: adapted from Schneider et al. (2014)

\section{Results and discussion}

The cross-case analyses are presented below. This presentation allows the comparison of cases and ease establishing themes or patterns (Creswell, 2013; Yin, 2009). In this study, the results of the case studies are classified into similar and dissimilar patterns. Table 3 provides information about each organization integration aspects and facilitates the comparison among them. The IMS conditioning factors are discussed at the end. The results obtained should be taken with caution as 6 cases, 3 per country, have been analyzed. Although according to Yin (2009) they allow generalizing to theoretical propositions (future research topics), they should not be generalized to populations.

\subsection{Similar patterns}

The aspects that are not presenting significant differences among the participant organizations are classified in this subsection.

\subsubsection{Integration strategy}

Five out of six organizations implemented the QMS first and then the EMS (see table 3), a common sequence in line with previous empirical findings (Douglas and Glen, 2000; Salomone, 2008; Bernardo et al., 2012b). The exception was organization 2S where the ISO 14001 standard was adopted first in order to address the specific environmental needs of the organization's activity, according to the IMS manager. Interestingly, two of the Greek companies have integrated more than two management systems. More specifically, 2G implemented the EMS and the health and safety MS simultaneously, while 3G has adopted simultaneously the ISO 14001 and the ISO 22000 (food safety) standards. 


\subsubsection{Integration methodology}

All cases followed the same integration method, i.e. by jointly adopting the common elements of the standards and MSs (see table 3). All companies found this methodology easier and making more sense than applying any other method or guideline in line with prior research (Karapetrovic et al., 2006). Organization 3G used a version of the common elements method, as the manager explained:

"The integration was based on the internal procedures or the structure of business, and we found the paragraphs of the standards that fit with them, in other words, we have adjusted the systems to our internal processes and try to make the standards fit for purpose”

It is noted that the manager of company 3G was recruited when the IMS was already in place.

Companies 1S and 1G developed their own information and technology systems to integrate the MSs and streamline the management of the IMS. Both companies highlighted the importance of using information technologies to facilitate the process:

"We have the integrated documentation in a single program to which all the personnel have access and this is enhancing the record control" (1S manager)

"To integrate, we have used a data base, a program developed by the owner of the organization, based on ACCESS code. The system uses the ISO protocol, with all the components of the systems in the data bases and we are managing them through the data base, everything is electronic" (1G manager)

Two out of the three Spanish organizations (1S and 3S) were aware of the national IMS standard, even though they chose not to use it. 3S IMS manager justified their decision by stating that:

"There was no added value expected by following a guideline not recognized outside Spain”,

none of them used it. Moreover, as 1S manager stated:

"If ISO decides to publish a standard for management systems integration we will not certify against it as we do not expect any benefits and costs would be very high"

Related to this integration aspect, the top management commitment was mentioned by organization 2G. The lack of top management commitment and the lack of the strategic perspective of the MSs is related with the low degree of integration at all aspects examined. Moreover, it is the only organization that does not perform any integrated audits, either 
internal or external, and, thus, lags significantly from all the others. In this context, 2G quality manager states that:

"We did not use any software to manage the integrated part. We have offers from software companies, but senior management has denied them. We have intranet and even though I requested a while ago to input information on the systems' procedures, etc. in order to make it accessible to all employees, I have not the permission to do it yet"

In the words of the organization's general manager:

"Integrating the two management systems would only ask for more resources and without adding any value"

\subsubsection{Integration level}

The integration of policies, objectives, documentation, resources and processes was evaluated as not integrated, partially integrated and fully integrated. For the human resources the number of people assigned to the management of the IMS was inquired. Particularly related to human resources, in most participating companies, the IMS is managed by a team, except for organization $2 \mathrm{G}$ where a single person is appointed as quality and environmental manager.

Questions on the IMS documentation and access on the actual documents (written manual, procedures, forms, records) investigated the degree of integration - formal (described) and actual (actual integrated usage of forms and procedures). The IMS managers were also interviewed on the integration of processes, such as planning, product realization, resource management, non-conformities control, preventive and corrective actions. The gathered data was compiled and formed an aggregate MS integration level for each case unit. Four out of the six organizations, two Spanish and two Greek, declared having the MSs fully integrated whereas in the other two cases, organizations have reached a partial integration level.

In organization 2G, which has partially integrated its MSs, the respondent stated that:

"I am the only responsible for all systems and I need help to integrate them. The culture of management systems began when I arrived to the organization, and the management does not give me the necessary resources and support”

His intention is to have all the systems integrated, but MSs are not seen of strategic importance for the organization's competitiveness by the top management. On the opposite side, organization 1G's manager declares:

"I do not understand another way of managing them" 
Regarding the elements of the integrated systems, i.e. objectives, processes and resources (as identified in the literature), in the six organizations, the processes are integrated at a higher level than the resources and the objectives (similar to Bernardo et al., 2009). For example, in organization 1S they:

"Have both MSs partially integrated and try to increase the level each time the opportunity rises to do it”

\subsubsection{Benefits and difficulties of the integration process}

It is noteworthy that all respondents were satisfied with the integration of MSs, according to their statements during the fieldwork.

As shown in table 3, more benefits than difficulties were encountered. More specifically, Spanish companies highlighted as benefits: the reduction of bureaucracy (less paperwork and easier management using information technologies), the exploitation of synergies (common aspects are merged making the IMS becoming more efficient), the mitigation of redundancies, and the methodical and unified management. This last benefit has also been highlighted by organization 1G. For Greek organizations decreasing cost (related with efficiency increasing) and improving the organization's resources and time management are the most highlighted benefits. It is noticeable that except for the control of bureaucracy, all other benefits have been recognized by two out of the three organizations in each country.

Two Spanish organizations and one Greek have declared encountering no difficulties. According to the $2 \mathrm{~S}$ manager:

"We do not consider integration difficult, since we are a small organization and this gives us a great advantage when it comes to the integration of MSs"

The QMS-EMS manager in organization 3G stated that:

"This integrated system facilitated the adoption of more management systems standards, such as the ISO 22000"

Among the major constraints identified by the Greek organizations are the increased bureaucracy, the training cost and the lack of resources, while a Spanish organization (1S) met difficulties when identifying and writing down the procedures and the forms of the IMS documentation. Country-specific drawbacks emerged when the Greek interviewees identified the lack of state-funding, the limited number of IMS-competent auditors and the lack of customer demand. Organization 1G IMS manager emphasized that:

"It is hard to find IMS aware auditors - qualified to perform integrated audits" 
Table 3. Comparative case analysis

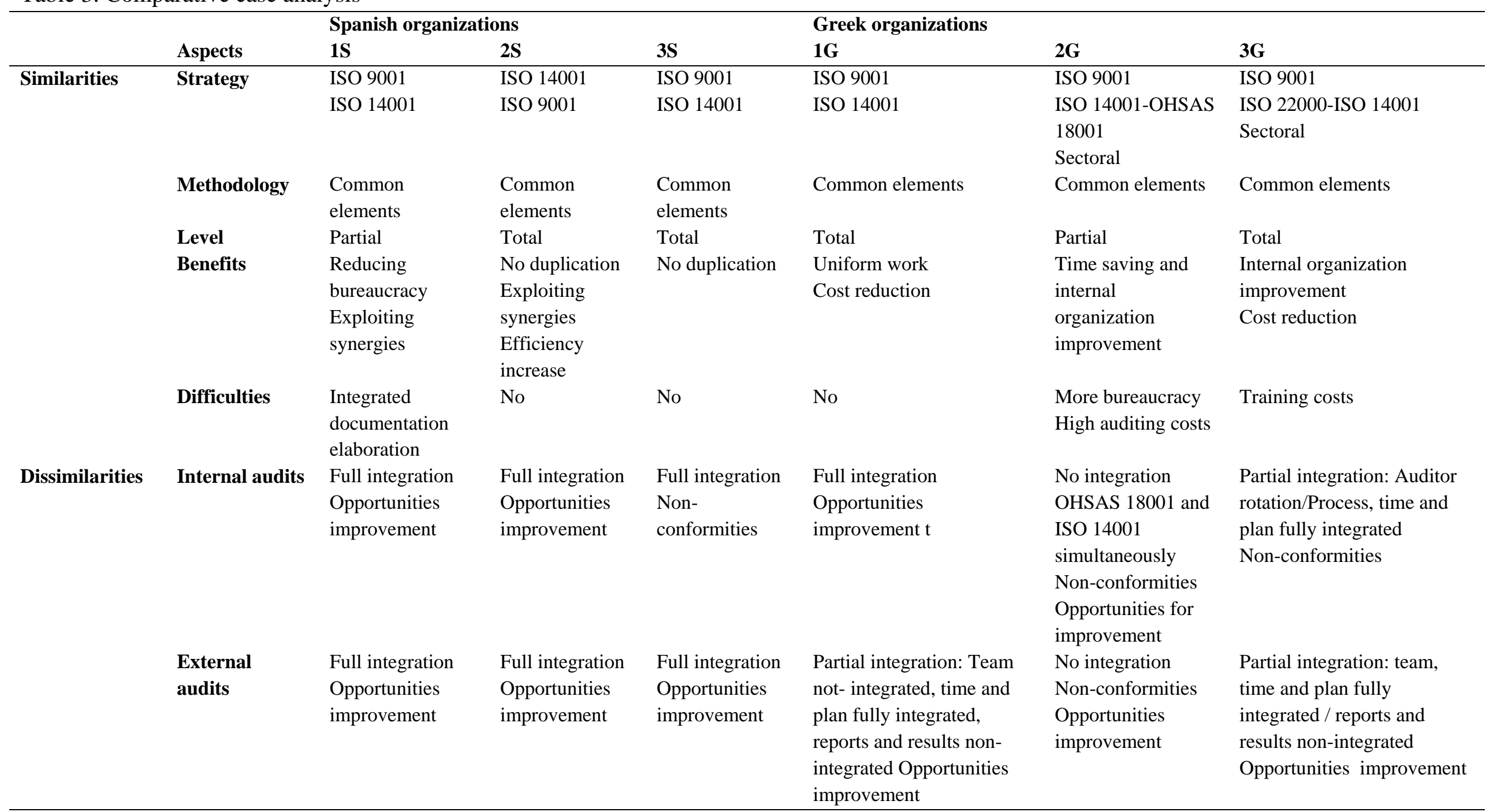


2G EMS manager argued that:

"There is lack of motivation by the state authorities to integrate". He mentioned that "the ISO 9001 and ISO 14001 standards adoption was subsidized in the past via EU funds. With regard to the ISO 14001 standard and the EMAS (environmental management and audit scheme) regulation adoption there are specific regulatory and financial incentives. However, it seems that Greek government leaves IMS out of its current MS policy, so far"

\subsection{Dissimilar patterns}

The aspect that is significantly different when comparing the participant organizations in both countries is the integration of audits.

The audits integration level was measured against certain criteria, as specified in the literature review section, i.e. how integrated are the team(s), time, plan(s), report(s), and results of the audits.

Spanish companies have fully integrated both the internal and the external audits, i.e. the audit team is the same for all systems, the audit is carried out simultaneously for all norms, the audit plan and the final audit report are consolidated, and the audit remarks include suggestions for opportunities to improve the implementation of each system and integration (see table 3). The only difference is found in organization 3S, where the internal audits merely detect non-conformities. Companies 2S and 3S followed a guideline during the audit, i.e., the organization 2S followed the ISO 19011 standard for the internal audit, and 3S shares the audit guideline adopted by the external auditors. Thus, the same level is achieved both within the organizations and between them.

The integration of audits varies across Greek cases (see table 3). The organization $1 \mathrm{G}$ has the internal audits fully integrated and the external audits only partially integrated:

"The first day the auditors audit the common elements of the systems (the integrated system), and the second, each auditor audits one of the systems"

In organization 2G, the audits are not integrated, but there is some evidence of integration, since in the internal audits the same team audited simultaneously the environmental and health and safety MSs. The integrated audit report included nonconformities and opportunities to improve the implementation of each system:

"The external audits are performed by three external auditors. All three conduct the ISO 9001 compliance audit, and then one is performing the ISO 14001 compliance audit while another carries out the ISO 22000 compliance audit. This happens because the ISO 14001 accredited auditor lacks accreditation to conduct ISO 22000 audits and vice versa" 
For the external audits, non-conformities have been reported as well as opportunities to improve the implementation of each system including integration.

In organization $3 G$ both audits are partially integrated. The audits elements that are fully integrated are the audit team, time and plan. The internal auditors perform compliance audits limited to the identification of non-conformities against the standards' requirements, whilst the external auditors add value by suggesting measures to improve the implementation and integration of the MSs, as well. Moreover, organization 3G uses a guideline for the internal audits.

Thus, Greek organizations present different levels of audit integration both for internal and external audits and also compared to the other Greek organizations.

\subsection{Factors conditioning the IMS implementation}

The comparative analysis between Greece and Spain regarding the IMS implementation, based on the 6 organizations analyzed, highlights that there are more similarities than dissimilarities (see table 3). All the integration aspects are similar or a common pattern could be easily identified, but this is not the case for the audits. The Spanish organizations have fully integrated their audits both internal and external; while the Greek organizations have different levels of integration of internal and external audits. These results are similar to Simon and Douglas (2013), as the main difference was also found in the internal audits, but not for the external audits as they were not analyzed in those countries.

Taking the abovementioned into account, in this subsection the factors that could be considered in the future research on IMS are discussed (Eisenhardt, 1989; Einsenhardt and Graebner, 2007; Yin, 2009). These factors could condition the integration of MSs within organizations in each country as well as its diffusion across countries. This discussion is based on the results of the 6 case studies presented but should be taken with caution as this is an exploratory research. However, the results obtained of the qualitative study together with the existing literature analyzed (see the literature review section), allow the proposal of these factors which should be confirmed with future research. Figure 7 shows the relationship among them.

The first factor to be discussed is the certification rates of individual MSs, as the comparison presented in this paper has been done considering that both countries, Greece and Spain, have different levels of ISO 9001 and ISO 14001 certification rates. According to the findings, the only dissimilarity found in the cases analyzed is in the integration of audits both internal and external. This result, for the internal audits, is similar as in Simon and Douglas (2013), in which organizations in Spain and UK were compared. In that paper, the organizations analyzed in both countries presented similar certification rates as both countries have been leading the certificates of ISO 9001 and ISO 14001 at a worldwide level (ISO, 2015). But there is no information about the level of integration of their external audits. 
Thus, it could be stated, based on this paper and Simon and Doulgas (2013)'s findings that the certification rate of individual MSs is not conditioning the IMS implementation as countries with similar or dissimilar certification rates are found to have different levels of internal audits integration. The contribution of the current paper is that the main difference found regarding the audits is for the integration of external audits, not analyzed previously in the literature comparing organizations in different countries (Simon and Douglas, 2013). But this dissimilarity between the integration level of internal and external audits within organizations has been identified in the literature (Bernardo et al., 2010, 2011). As the Spanish organizations achieved greater levels of integration of their external audits, it could be stated that as higher the certification rate is, greater seems to be the integration of the external audits. In other words, as the certification rates of individual MSs are higher in Spain, it seems that as more MSs certificates have the country, more demand for external audits and thus, certification bodies need more trained and skilled auditors to cover this demand. So, another important factor is the auditors' experience and competence.

In the current paper, the Spanish companies integrated fully their internal and external audits whereas Greek organizations conducted separate, partially or fully integrated first- and thirdparty audits. Particularly, organization 2G differs from the others, since it is the only one that does not integrate its MS audits, even though the MSs are partially integrated (similar results can be found in Bernardo et al., 2011). The lack of skilled IMS auditors was reported as a key drawback by the Greek informants (similar as in Zeng et al., 2007).

In line with the abovementioned, the following proposition is posed:

P1: The certification rates of individual MSs condition the integration of external audits through the external auditors' experience and competence

As only two studies focus on the certification bodies' role on the integration of external audit have been published (Kafel and Sikora, 2010; Wilkinson and Dale, 1998), more research is needed in this area (as also proposed in Heras-Saizarbitoria and Boiral, 2013).

Another factor related to the integration is the state or government support. Greek companies identified the lack of state-funding as an impediment to integrate. This "expectation of state support" expressed by the Greek organizations in this study is highlighted in prior research, as well. More specifically, Lagodimos et al. (2007) stress that "in order to increase national awareness on quality and environmental issues, the implementation of standardized ISO management systems has traditionally been heavily subsidized by the Greek state, mainly through EU funds". In addition, it was emphasized by Greek informants that state authorities have fostered the adoption of individual MSSs in the past within legislation. However, IMS remains out of the government's strategic agenda. On the other side, Spanish organizations did not comment on this factor, thus the need for external support could be related to the available resources of the organizations as well as other factors such as the certification rates of individual MSs, because is the non-leading country commenting on this lack of support; existence of an IMS guideline, etc. More 
research is needed in order to define the state's role in the integration process. Thus, the following proposition is presented bearing in mind that IMS evolution seems to follow a similar patter as individual MSs (see Delmas and Montiel, 2008, for government support):

P2: The state support could foster the integration of MSs as it did with individual MSs adoption

There is another factor, more internally-driven, to be analyzed in the future and is how the internalization of MSs could condition the integration of MSs. The internalization of MSs is the process by which internal operations are accepted as usual and become a factor difficult to imitate (Prajogo, 2011). Based on the results of this study, it seems clear that the experience in managing the MSs cannot be defined either by the number of certificates (more certificates does not mean better management) neither by the amount of time the organizations of the country have been certified (a long period of time with the certification cannot guarantee better management), because the important aspect is how deep the organization has implemented the MSs making them to become a routine (Arifin et al., 2009; Heras-Saizarbitoria, 2011; Tarí et al., 2013). In other words, which is the degree of internalization of these MSs. Considering this, the following proposition could be presented:

P3: Greater levels of MSs internalization will lead to a greater experience in managing MSs and this, to a higher level of MSs integration

Related to this is the top management commitment, which has been highlighted by participant organizations as a common denominator for IMS advanced integration level. It is worth underlining that the organization $2 \mathrm{G}$, the one with negative top management commitment, reaches the lowest integration level of both the MSs and the audits. Moreover, lack of technical resources (e.g., IMS-dedicated information and technology systems) is also emphasized by Greek companies and related with lack of top management commitment. Marketing incentives to integrate are missing, that might yield a "signaling" effect such as when individual MSs are implemented (Terlaak and King, 2006). Hence, according to these organizations, no direct financial benefits are anticipated by IMS implementation (in contrast of Ferrón-Vílchez and Darnall, 2016). Furthermore, it is found that the IMS added-value potential is not spread in Greek organizations. These are mostly the reasons why Greek senior managers show no interest in allocating resources to the IMS. These findings are in line with prior research (Almeida et al., 2014; Gianni and Gotzamani, 2015) stressing that top management commitment is strongly "attached" with the strategic orientation of an IMS and its performance, in turn. Thus, the following proposition could be posed:

P4: Top management commitment conditions the integration of MSs, i.e., greater levels of top management commitment lead to a higher MSs integration level and on the contrary, lower levels of top management commitment lead to a lower level or no MSs integration

Finally, a better integration of MSs could increase the number of new MSs implemented and integrated (Rocha et al., 2007). According to the findings obtained in this paper and previous 
literature (see e.g., Alonso-Almeida et al., 2013), the sectoral MSs are increasing as organizations find them to fit better with their activities.

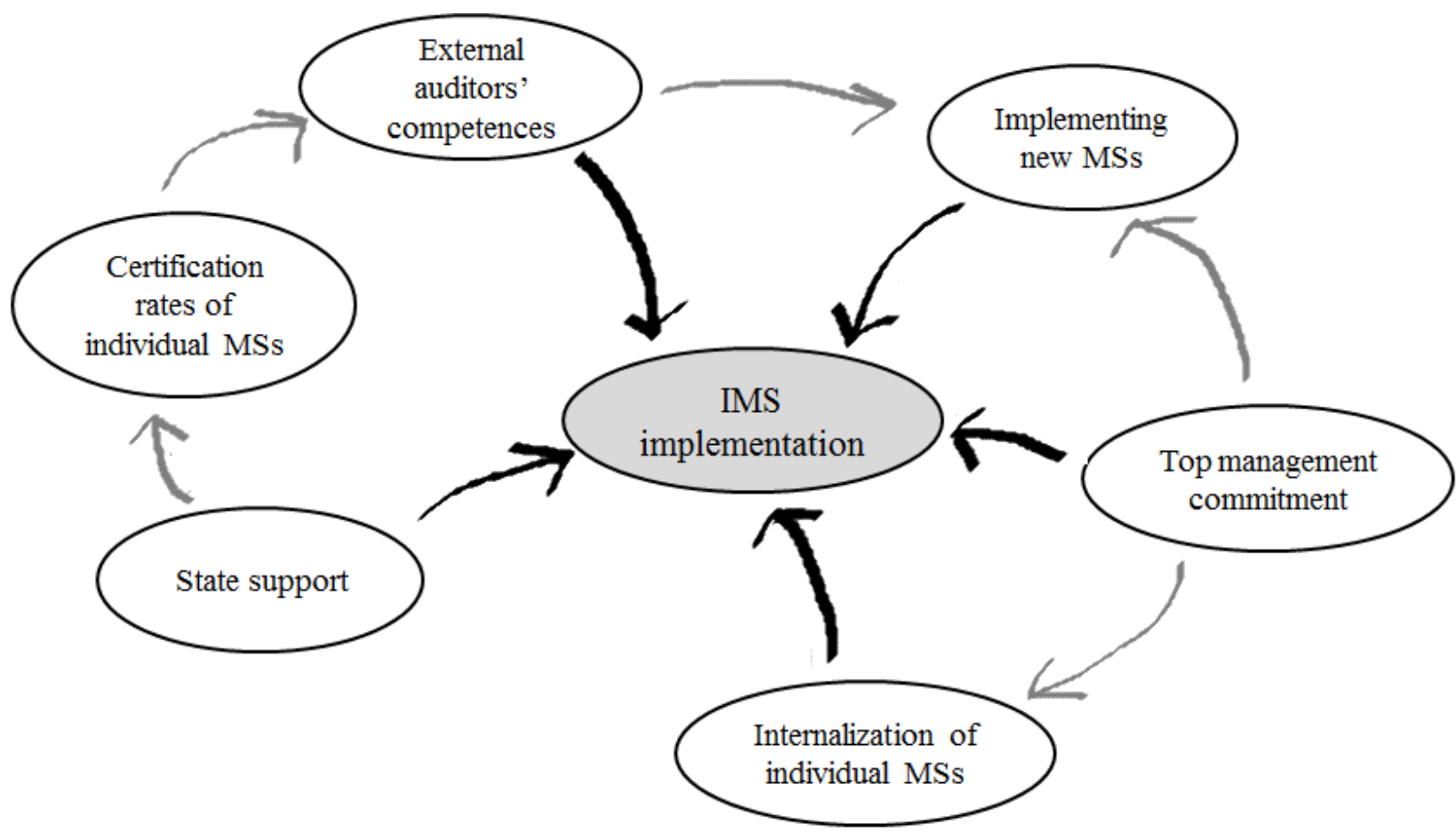

Figure 7. Factors conditioning the IMS implementation (proposal of a research agenda for future research)

Source: Own elaboration

\section{Conclusions}

The aim of this paper is to analyze and compare the implementation of IMS among organizations located in two countries, Greece and Spain, which have different ISO 9001 and ISO 14001 certification rates. With the results obtained of the 6 case studies, 3 per country, the following conclusions could be presented considering the exploratory nature of this research.

First, the integration of MSs is a similar process in the organizations analyzed in both countries. Although the similarity is not total, small differences have been detected. For example, the majority of companies follows the same strategy, i.e., implementing first the ISO 9001 and then the ISO 14001; achieves the highest level for the IMS; highlights similar difficulties and benefits of the process, and all of them use the analysis of the common elements as a methodology to integrate. The only integration aspect that is different is the audits both internal and external. Spanish organizations have internal and external audits fully integrated while the Greek organizations have different levels of audits integration. The external audits are integrated at a lower level than the internal, if they are integrated. Thus, for the organizations analyzed, it is shown that those internal aspects controlled by the 
organization are integrated at a higher level than those external or not controlled, as the external audits.

Second, based on the 6 cases results and the existing literature analyzed in this paper (see section 2), different future research lines aiming to reduce the differences between the organizations of the analyzed countries have been proposed, mainly focus on the external audits. The certification rates of individual MSs has not been found as a conditioning factor for the implementation of IMS in the participant organizations but it could be conditioning the external audits (this is the first contribution of this study), jointly with the external auditors' competences and knowledge. The state support has also been discussed as an enabler for the integration process, mainly by Greek organizations, and also related to the certification rates and other factors such as the existence of an integration guideline.

At another level, both the internalization of MSs and the top management commitment play an important role in the integration process. Both are positively related with the IMS because as more internalized are the MSs and top management is committed (as in the majority of the cases presented), a higher level of integration could be reached. In turn, internalization and top management commitment are also closely related. These aspects are also important for the maintenance of the IMS. As the implementation process has been analyzed and conditioning factors identified, the next step would be focusing on analyzing the IMS sustainability. It would be guaranteed by the continuous improvement process but analyzing the impact on stakeholders and on organizations' performance would help in measuring the benefits of the IMS and its maintenance. This would mean analyzing the impact of the IMS in terms of economic, social and environmental issues. According to the existing literature (see e.g., Bernardo et al., 2015; Matias and Coelho, 2011; Rebelo et al., 2016), the IMS benefits are greater than the sum of the benefits obtained by the individual MSSs, the organization is more efficient, leaner and the value added is improved, but this has been mainly analyzed for the ISO 9001 and ISO 14001 MSSs. Thus, the quality and environmental aspects take profit of the integration, i.e., the IMS provides quality and environmental benefits for the organizations which implement it. The benefits for the other issues, social and economic, as well as their interrelationships need to be more analyzed, as well as the extension of the IMS through the value chain. Finally, following the same line, if the implementation and integration are well-done, it would be easier to implement and integrate new MSs in the future which will contribute to the IMS sustainability.

According to the abovementioned, it could be concluded, based on the results obtained, that the internal aspects of the integration process in the analyzed organizations in the two different countries are similar, maybe because of the knowledge and experience gained when managing the MSs individually. However, the external aspects of the integration process are different depending on the organizations analyzed in the countries and this difference could be explained by the different certification rates of individual MSs as well as for the external auditors' competences and skills. To the best of the authors' knowledge, this is one of the first studies analyzing and identifying internal and external conditioning factors of the integration process based on a comparative study (which should be confirmed in future 
research), in this case, among organizations in Greece and Spain, two countries with different certification rates of individual MSSs (this is the second contribution of this research).

The implications that could be drawn of this qualitative and exploratory research are for the academia, organizations and certification bodies. For the former, different research lines (conditioning factors) have been proposed to know better and more in-depth the integration of MSs process. For organizations, because they could realize how important a good implementation of MSs is, as internalization could lead to higher levels of integration. In addition, choosing the appropriate certification body to pass the external audits could be also learnt. For them, the certification bodies, having well-trained and skilled auditors to perform external integrated audits will be very important to survive in the market, not only the national but also the international, in which it could also be a business opportunity.

The main limitation is the sample size. Three cases per country, although for a qualitative and exploratory research as the present one allows comparison and theoretical propositions generalization, the results cannot be extrapolated for all the countries (depending on the certification rate of individual MSs) and all the conclusions extracted should be taken with caution. No generalization to populations or universes could be done. More research adding more countries with different certification rates (maximum diversity of the sample) in the analysis is needed to minimize this limitation.

Finally, future works would focus mainly on analyzing the identified factors conditioning the IMS implementation.

\section{Acknowledgements}

The field work was financed by a mobility grant of the Faculty of Economy and Business of the Universitat de Barcelona.

\section{References}

Abad, J., Dalmau, I., Vilajosona, J., 2014. Taxonomic proposal for integration levels of management systems based on empirical evidence and derived corporate benefits. Journal of Cleaner Production. 78, 164-173.

AENOR, 2005. UNE 66177: Sistemas de gestión. Guía para la integración de los sistemas de gestión, AENOR, Madrid, Spain.

Albuquerque, P., Bronnenberg, B., Corbett, C., 2007. A spatiotemporal analysis of the global diffusion of ISO 9000 and ISO 14000 certification. Management Science. 53, 451-68.

Alonso-Almeida, M.M., Marimon, F., Bernardo, M., 2013. Diffusion of Quality Standards in the Hospitality Sector. International Journal of Operations and Production Management. 33, 504-527.

Almeida, J., Domingues, P., Sampaio, P., 2014. Different perspectives on management systems integration. Total Quality Management \& Business Excellence, 25: 338-351

Arifin, K., Aiyub, K., Awang, A., Jahi, J.M., Iten, R. 2009. Implementation of integrated management system in Malaysia: The level of organization's understanding and awareness. European Journal of Scientific Research, 31, 188-195. 
Asif, M., de Bruijn, E.J., Fisscher, O.A.M., Searcy, C., Steenhuis, H., 2009. Process embedded design of integrated management systems. International Journal of Quality \& Reliability Management. 26, 261-282.

Asif, M., de Bruijn, E.J., Fisscher, O.A.M., 2010. Meta-management of integration of management systems. The TQM Journal, 22, 570-582.

Beckmerhagen, I.A., Berg, H.P., Karapetrovic, S.V., Willborn, W.O., 2003. Integration of management systems: focus on safety in the nuclear industry. International Journal of Quality and Reliability Management. 20, 210-228.

Bernardo, M. 2014. Integration of management systems as an innovation: a proposal for a new model. Journal of Cleaner Production. 82, 132-142

Bernardo, M., Casadesús, M., Karapetrovic, S., Heras, I.. 2009. How integrated are environmental, quality and other standardized management systems? An empirical study. Journal of Cleaner Production. 17, 742-750

Bernardo, M., Casadesús, M., Karapetrovic, S., Heras, I., 2010. An empirical study on the integration of management system audits. Journal of Cleaner Production. 18, 486-495.

Bernardo, M., Casadesús, M., Karapetrovic, S., Heras, I., 2011. Relationships between the integration of audits and management systems: An empirical study. Total Quality Management. 26, 659-672.

Bernardo, M., Casadesús, M., Karapetrovic S., Heras, I., 2012a. Do integration difficulties influence management system integration levels? Journal of Cleaner Production, 21, 23-33.

Bernardo, M., Casadesús, M., Karapetrovic, S., Heras, I., 2012b. Integration of standardized management systems: does the implementation order matter? International Journal of Operations \& Production Management. 32, 291-307.

Bernardo, M., Simon, A., Tarí J.J., Molina-Azorín, J.F., 2015. Benefits of management systems integration: a literature review. Journal of Cleaner Production. 94, 260-267.

BSI, 2012. PAS 99 Specification of common management system requirements as a framework for integration, British Standards Institution, London, UK.

Corbett. C.J., Kirsch, D.A., 2001. International diffusion of ISO 14000 certification. Production and Operations Management. 10, 327-342.

Creswell, J.W., 2013. Qualitative inquiry and research design. Choosing among five approaches. $3^{\text {rd }}$ edition. Sage Publications, Inc., Thousand Oaks, California, USA

Delmas, M., Montiel, I., 2008. The Diffusion of Voluntary International Management Standards: Responsible Care, ISO 9000, and ISO 14001 in the Chemical Industry. The Policy Studies Journal. 36, 65-93

Dansk Standard. 2005. DS 8001:2005. Ledelsessystemer. Copenhagen, Denmark: Vejledning i opbygning af et integreret ledelsessystem.

Denzin, N.K., Lincoln, Y.S., 2011. Introduction: the discipline and practice of qual-itative research, in: Denzin, N.K., Lincoln, Y.S. (Eds.), The Sage Handbook of Qualitative Research. 5th ed. Sage, London, pp. 1-19.

Domingues, J.P.T., Sampaio, P., Arezes, P.M., 2015. Analysis of integrated management systems from various perspectives. Total Quality Management \& Business Excellence. 26, 1311-1334.

Douglas, A., Glen, D., 2000. Integrated management systems in small and medium enterprises. Total Quality Management. 11, 686-690. 
Eisenhardt, K.M., 1989. Building Theories from Case Study Research. Academy of Management Review. 14, 532-550.

Eisenhardt, K.M., Graebner, M.E. 2007. Theory building from cases: opportunities and challenges. Academy of management Journal. 50, 25-32.

Eurostat. 2016. Statistics. Retrieved by [April, 2016]: http://epp.eurostat.ec.europa.eu/statistics_explained/index.php

Ferrón-Vílchez, V., Darnall, N., 2016. Two better than one: the link between management systems and business performance. Business Strategy and the Environment. 25, 221-240

Gianni, M., Gotzamani, K., 2015. Management systems integration: lessons from an abandonment case. Journal of Cleaner Production. 86, 265-276.

González, P., Rosario, M., Lambán, C., Pilar, M., 2014. Costs modelling applied to activities of integrated management. Key Engineering Materials. 615, 124-129

Heras-Saizarbitoria, I., 2011. Internalization of ISO 9000: an exploratory study. Industrial Management and Data Systems. 111, 1214-1237.

Heras-Saizarbitoria, I., Boiral, O., 2013. ISO 9001 and ISO 14001: Towards a research agenda on management system standards. International Journal of Management Reviews. 15, 47-65.

Hernandez-Vivanco, A., Bernardo, M., Cruz-Cázares, C., 2016. Relating Open Innovation, Innovation and Management Systems Integration. Industrial Management and Data Systems. 116, 1540-1556

Hoy, Z., Foley, A., 2015. A structured approach to integrating audits to create organizational efficiencies: ISO 9001 and ISO 27001 audits. Total Quality Management \& Business Excellence. 26, 690-702

ISO, 2008. The integrated use of management system standards, International Organization for Standardization, Geneva, Switzerland.

ISO, 2015. The ISO survey of management system standard certifications, International Organization for Standardization, Geneva, Switzerland.

Jadudová, J., Zelený, J., Hroncová Vicanová, J., Marková, I., 2016. Stakeholder management as part of integrated management system, Production Management and Engineering Sciences - Scientific Publication of the International Conference on Engineering Science and Production Management, ESPM 2015, pp. 119-123

Kafel, P., Sikora, T. 2010. Integrated management systems certification - survey results. Institute of Organization and Management in Industry „ORGMASZ”, 45-53

Karapetrovic, S., 2002. Strategies for the integration of management systems and standards. The TQM Magazine. 14. 61-67.

Karapetrovic, S., 2003. Musings on integrated management Systems. Measuring Business Excellence. 7, 4-13.

Karapetrovic, S., 2005. IMS in the M(E)SS with CSCS. International Journal - Total Quality Management and Excellence. 33, 19-25

Karapetrovic, S., Casadesús, M., 2009. Implementing environmental with other standardized management systems: Scope, sequence, time and integration. Journal of Cleaner Production. 17, 533-540. 
Karapetrovic, S., Jonker, J.. 2003. Integration of standardized management systems: searching for a recipe and ingredients. Total Quality Management \& Business Excellence. 14, 451-459.

Karapetrovic, S., Willborn, W.. 1998a. Integration of quality and environmental management systems. The TQM Magazine. 10, 204-213.

Karapetrovic, S., Willborn, W., 1998b. Integrated audit of management systems. International Journal of Quality \& Reliability Management. 15, 694-711.

Karapetrovic, S., Willborn, W., 2001. Audit systems: Concepts and practices. Total Quality Management. 12, 13-28.

Karapetrovic, S., Casadesús, M., Heras, I., 2006. Dynamics and integration of standardized management systems. An empirical study, Documenta Universitaria, GITASP 1, Girona, Spain.

Keman, H., 1993. Comparative Politics: New Directions in Theory and Method, VU Press, Amsterdam.

Kraus, J., Grosskopf, J., 2008. Auditing Integrated Management Systems: Considerations and Practice Tips. Environmental Quality Management. 18, 7-16

Lagodimos, A.G., Chountalas, P.T., Chatzi, K., 2007. The state of ISO 14001 certification in Greece. Journal of Cleaner Production. 15, 1743-1754.

Llach, J., Marimon, F., Bernardo, M., 2011. ISO 9001 diffusion analysis according to activity sectors. Industrial Management \& Data Systems. 111, 298-316.

Llonch, M., Bernardo, M., 2016. Simultaneous integration: a case study of an SME. 2nd International Conference on Quality Engineering and Management (University of Minho, Portugal). Proceedings book of the 2nd International Conference on Quality Engineering and Management, 100-111

Mak, L.M. 2015. Travel agencies’ perception of ISO 9001 certification. The TQM Journal. 27, 741-751.

Marimon, F., Casadesús, M., Heras, I., 2006. ISO 9000 and ISO 14000 standards: An international diffusion model. International Journal of Operations and Production Management. 26, 141-165.

Marimon, F., Llach, J., Bernardo, M., 2011. Comparative analysis of diffusion of the ISO 14001 standard by sector of activity. Journal of Cleaner Production. 19, 1734-1744.

Matias, J.C.O., Coelho, D.A., 2011. Integrated total quality managemen: beyod zero defects theory and towards innovation. Total Quality Management. 22, 891-910

Mezinska, I., Lapina, I., Mazais, J., 2015. Integrated management systems towards sustainable and socially responsible organization. Total Quality Management \& Business Excellence. 26, 469-481

de Oliveira, O.J., 2013. Guidelines for the integration of certifiable management systems in industrial companies. Journal of Cleaner Production. 57, 124-133.

Pal Pandi, A., Rajendra Sethupathi, P.J., Jeyathilaga, D., 2016. The IEQMS model for augmenting quality in engineering institutions - an interpretive structural modeling approach. Total Quality Management and Business Excellence. 27, 292-308

Prajogo, D.I. 2011. The roles of firms' motives in affecting the outcomes of ISO 9000 adoption. International Journal of Operations \& Production Management. 19, 78-100 
Prakash, A., Potoski, M. 2007. Investing up: FDI and the cross-country diffusion of ISO 14001 management systems. International Studies Quarterly. 51, 723-744.

Ragin, C.C. 2014. The Comparative Method: Moving beyond Qualitative and Quantitative Strategies, University of California Press, Los Angeles, CA.

Rebelo, M.F., Silva, R., santos, G., Mendes, P. 2016. Model based integration of management systems (MSs) - case study. The TQM Journal. 28, 907-932

Rocha, M., Searcy, C., Karapetrovic, S., 2007. Integrating Sustainable Development into Existing Management Systems. Total Quality Management \& Business Excellence. 18, 8392

SAI Global, 1999. AS/NZS 4581:1999. Management system integration - Guidance to business, government and community organizations, Sydney, Australia.

Salomone, R., 2008. Integrated management systems: experiences in Italian organizations. Journal of Cleaner Production. 16, 1786-1806.

Sampaio, P., Saraiva P., Rodrigues A.R., 2011. The economic impact of quality management systems in Portuguese certified companies. Empirical evidence. International Journal of Quality \& Reliability Management. 28, 929 - 950.

Sampaio, P., Saraiva P., Domingues P., 2012. Management systems: integration or addition? International Journal of Quality \& Reliability Management. 29, 402 - 424.

Santos, G., Mendes, F., Barbosa, J., 2011. Certification and integration of management systems: the experience of Portuguese small and medium enterprises. Journal of Cleaner Production. 19, 1965-1974.

Satolo, E.G., Calarge, F.A., Cauchick Miguel, P.A., 2013. Experience with an integrated management system in a sugar and ethanol manufacturing unit: Possibilities and limitations. Management of Environmental Quality: An International Journal. 24, 710-725.

Schneider, L., Wallenburg, C.M., Fabel, S., 2014. Implementing sustainability on a corporate and a functional level. International Journal of Physical Distribution \& Logistics Management. 44, 464-493.

Searcy, C., Morali, O., Karapetrovic, S., Wichuk, K., McCartney, D., McLeod, S., Fraser, D., 2012. Challenges in implementing a functional ISO 14001 environmental management system. International Journal of Quality and Reliability Management. 29, 779-796

Siggelkow, N. 2007. Persuasion with case studies. Academy of Management Journal. 50, 20 24.

Simon, A., Yaya, L.H.P., 2012. Improving innovation and customer satisfaction through systems integration. Industrial Management \& Data Systems. 112, 1026-1043

Simon, A., Douglas, A., 2013. Integrating management systems: Does the location matter? International Journal of Quality and Reliability Management. 30, 675-689.

Simon, A., Bernado, M., Karapetrovic, S., Casadesús, M., 2011. Integration of standardized environmental and quality management systems audits. Journal of Cleaner Production. 19, 2057-2065. 
Simon, A., Bernado, M., Karapetrovic, S., Casadesús, M., 2013. Implementing integrated management systems in chemical firms. Total Quality Management \& Business Excellence. 24, 294-309.

Simon, A., Yaya, L.H.P., Karapetrovic, S., Casadesús, M., 2014. An empirical analysis of the integration of internal and external management systems audits. Journal of Cleaner Production. 66, 499-506.

Tarí, J.J., Heras-Saizarbitoria, I., Pereira, J., 2013. Internalization of quality management in service organizations. Managing Service Quality. 23, 456-473

Terlaak, A., King, AA., 2006. The effect of certification with the ISO 9000 quality management standard: A signaling approach. Journal of Economic Behavior \& Organization. 60, 579-602.

Wilkinson, G., Dale, B., 1998. System integration: the views and activities of certification bodies. The TQM Magazine. 10, 288-292.

Wilkinson, G., Dale, B.G., 1999. Integrated management systems: An examination of the concept and theory. The TQM Magazine. 11, 95-104.

Yin, R.K., 2009. Case Study Research. Design and Methods, 4th ed, Sage Publications Inc., Thousand Oaks, CA.

Zeng, S., Shi, J.J., Lou, GX., 2007. A synergetic model for implementing an integrated management system: an empirical study in China. Journal of Cleaner Production. 15, 17601767.

Zeng, S., Xie, X.M., Tam, C.M., Shen, L.Y. 2011. An empirical examination of benefits from implementing integrated management systems (IMS). Total Quality Management \& Business Excellence, 22, 173-186.

Zutshi, A., Sohal, A.S. 2005. Integrated management systems: The experiences of three Australian organisations. Journal of Manufacturing Technology Management. 16, 211-232. 